\title{
Dosages of androgenic hormones in adolescent patients with severe acne
}

\author{
(iD) Marisa Gonzaga da Cunha' \\ (iD) Caio Moraes ${ }^{1}$ \\ Giovana Cebrian ${ }^{1}$ \\ (D) Rafaela Ferreira da Silva ${ }^{1}$ \\ Sônia Isabel Friedlaender Reple ${ }^{2}$ \\ (D) Carlos D'Apparecida Machado Filho ${ }^{1}$ \\ (iD) Fernando Luiz Affonso Fonseca ${ }^{2,3}$
}

\begin{abstract}
1. Disciplina de Dermatologia da Faculdade de Medicina do ABC, Av. Príncipe de Gales, 821, CEP 09060-650, Santo André, SP, Brasil; 2. Laboratório de Análises Clínicas da Faculdade de Medicina do ABC, Av. Príncipe de Gales, 821, CEP 09060-650, Santo André, SP, Brasil; 3. Departamento de Ciências Farmacêuticas, Universidade Federal de São Paulo, R. Prof. Artur Riedel, 275, CEP 09972-270, Diadema, SP, Brasil.
\end{abstract}

http://dx.doi.org/10.1590/1806-9282.66.1.36

\section{SUMMARY}

OBJECTIVE: Acne vulgaris in female adolescents, when severe or accompanied by other signs of androgenization, may represent a sign of hyperandrogenemia often underdiagnosed, which will have harmful consequences for adult life. The objective of this cross-sectional and retrospective study was to demonstrate the incidence of hormonal changes in the cases of female adolescents with severe or extensive acne, with or without other signs of hyperandrogenism, and propose a hormonal research pattern which should be indicated in order to detect early hyperandrogenemia.

METHODS: The medical records of 38 female patients aged between 9 and 15 years old with grade I/ and/or III acne were analyzed. The dehydroepiandrosterone sulfate, dehydroepiandrostenedione, and androstenedione, total testosterone, and dihydrotestosterone sulfate hormones were required prior to initiation of treatment. The hormonal dosages were performed in the serum after at least 3 hours of fasting by means of radioimmunoassay tests.

RESULTS: Of the 38 patients included, $44.7 \%$ presented changes in androgen levels (hyperandrogenemia), and the two most frequently altered hormones were DHEA and androstenedione, with the same incidence (23.6\%).

CONCLUSIONS: The correct and early diagnosis provides an effective and agile approach, including antiandrogen therapy, with the purpose of avoiding the reproductive and metabolic repercussions, besides controlling the inflammatory picture and avoid aesthetic complications.

KEYWORDS: Acne vulgaris. Adolescent. Androgens. Hyperandrogenism.

\section{INTRODUCTION}

The human skin is the target of a large number of chemical messengers, among which there are many hormones. The hormonal effect on the development of secondary sexual characteristics from puberty and the capacity of the pilosebaceous unit for producing and releasing hormones is already known. Hormones, among them the steroids, biologically affect the skin through high-affinity receptors in both nuclear and cytoplasmic membranes'.

When adolescence starts, there is a physiological elevation of serum levels of androgens in both sexes ${ }^{2}$. The hormonal trigger, and the resulting increase in 
the androgen production, especially the increase in DHEAS levels (dehydroepiandrosterone sulfate), a testosterone precursor ${ }^{3.4}$, acts on the sebaceous glands and promotes the excessive production of sebum, leading to the abnormal detachment of keratinocytes and the obstruction of the follicle opening, with consequent formation of the microcomedo ${ }^{5}$, which is considered the initial stage of subclinical acne lesions $^{6}$. The accumulation of sebum and the modification of its composition in the sebaceous gland favor the proliferation of gram-positive bacteria Propionibacterium acnes in genetically predisposed individuals ${ }^{5}$. This, in turn, leads to the release of cytokines such as interleukins IL- 6 and IL- 8 by the infundibular keratinocytes and IL- 8 and IL-12 by macrophages, as well as pro-inflammatory mediators, resulting in the induction of inflammatory signaling in the pilosebaceous unit, which is an essential component in the initial process of acne lesions ${ }^{7.8}$.

Thus, the key factors involved in the acne pathogenesis are classically summarized as 1) androgen hormone trigger, 2) sebaceous hypersecretion, 3) follicular hyperkeratosis with microcomedo formation, 4) proliferation of P. acnes, and 5) resulting inflammatory response $e^{9.10}$.

Acne vulgaris is one of the most common pathologies in dermatology clinics, and a study with adolescents aged over 16 years in New Zealand estimated that $91 \%$ of boys and $79 \%$ of girls suffer from acne ${ }^{11}$. It can be observed at any age, but is more prevalent and more severe during puberty, with peaks of prevalence at 14-17 years of age in women and at 16-19 years in man. It tends to resolve spontaneously between the age of 20-25 years in both sexes, although this age is being prolonged ${ }^{12}$. It mainly affects the face, trunk, and back, with injuries ranging from comedos to inflammatory nodules ${ }^{13}$.

In this context, the presence of acne in female adolescents aged between 12 and 17 years is expected. However, when it presents as a severe and extensive condition accompanied by other signs of androgenization, such as hirsutism and/or an increase of fat deposition in the abdominal subcutaneous tissue, i.e., with a male pattern of deposition with or without weight gain ${ }^{14}$, the possibility of increased serum levels of androgens should be contemplated. Since the situation described is not always valued by dermatologists, leading to underdiagnosed cases of hyperandrogenism, many of these patients carry its harmful consequences into adult life, such as a body with a male pattern, acne scars, and hirsutism.

The objective of this retrospective cross-sectional study is to demonstrate the incidence of hormonal changes in cases of female adolescents, aged between 9 and 15 years, with severe or extensive acne, accompanied or not by other signs of hyperandrogenism, and propose a hormonal investigation pattern action that should be indicated for the early detection of a hyperandrogenemia scenario, avoiding its future aesthetic and metabolic manifestations.

\section{METHOD}

\section{Patients}

We analyzed the medical records of female patients treated in the outpatient clinic of Acne in Adult Women of the Dermatology Discipline of FMABC between 2010 and 2016. We included patients aged between 9 and 15 years old with papular-pustular acne (grade II) or cystic acne (grade III) affecting the face, with over 15 inflammatory lesions at the time of examination, with or without acne scars, with or without hirsutism and hypertrichosis. We excluded patients aged below 9 above 15 years old with acne grade I, grade II with less than 15 lesions at the moment of the examination and without acne scars, as well as patients in use of topical or systemic corticosteroids, vitamin supplements, anticonvulsants, and hormonal treatments, including anabolic steroids. This study was approved by the Research Ethics Committee of the Faculty of Medicine of ABC (87780418.5.0000.0082). All the people responsible for the participants read and signed the Informed Consent Form.

\section{Hormonal Dosage}

The dehydroepiandrosterone sulfate (DHEAS), dehydroepiandrosterone (DHEA), androstenedione, total testosterone, and dihydrotestosterone (DHT) were systematically requested in the first consultation, before the initiation of treatment. The serum hormonal measurements were performed after at least 3 hours of fasting by radioimmunoassay examinations. The measurement methods used followed the international standardization for each of the respective hormones and the good practices; the values obtained are considered in accordance with the standards recommended in the guidelines for clinical analysis ${ }^{15}$. 


\section{RESULTS}

We analyzed the medical records of 38 female patients aged between 9 and 15 years old, with acne grade II and/or III affecting the face; 23 patients also had lesions on the trunk and/or back (Figure 1). The onset of the lesions occurred between the ages of 9 to 15 years (mean of 12.8 years). The analysis showed that 17 patients ( $44.7 \%$ of the total) had high results in at least one of the hormones measured (the distribution is described in Table 1) in an isolated way or with combined high levels; 9 patients (23.6\%) had more than one abnormal results, and DHEA and androstenedione was the combination more frequently observed (five patients). It should be noted that 23 patients ( $60.5 \%$ of the total) had hypertrichosis or hirsutism associated, based on the Ferriman-Gallway scale. Of the total number of patients, 17 reported menstrual irregularities (44.7\%). Of the 12 patients who had the onset of symptoms at ages 14 or 15 years, i.e., two or more years after menarche, five had hormonal abnormalities and four, menstrual irregularities.

Of 38 medical records analyzed, 25 contained ultrasounds of the pelvic region; 17 patients (68\%) presented polycystic ovaries upon examination.

For the diagnosis of polycystic ovary syndrome (POS), according to the Rotterdam consensus, two of the following data must be taken into account: hyperandrogenemia or hyperandrogenism, menstrual irregularities, and polycystic ovaries found on ultrasound. Thus, among the 38 patients studied, 23 (60.5\%) presented the criteria for a POS diagnosis ${ }^{16}$.

It should be noted that for patients with hyperandrogenemia and normal menstrual cycles, serum 17-OH (17-hydroxy-progesterone) measurement was subsequently requested to evaluate the possibility of benign adrenal hyperplasia. Two patients presented high values, thus being diagnosed with the condition.

FIGURE 1. A 12-YEAR-OLD PATIENT WITH EXTENSIVE CYSTIC ACNE ON THE FACE (A) AND BACK (B).

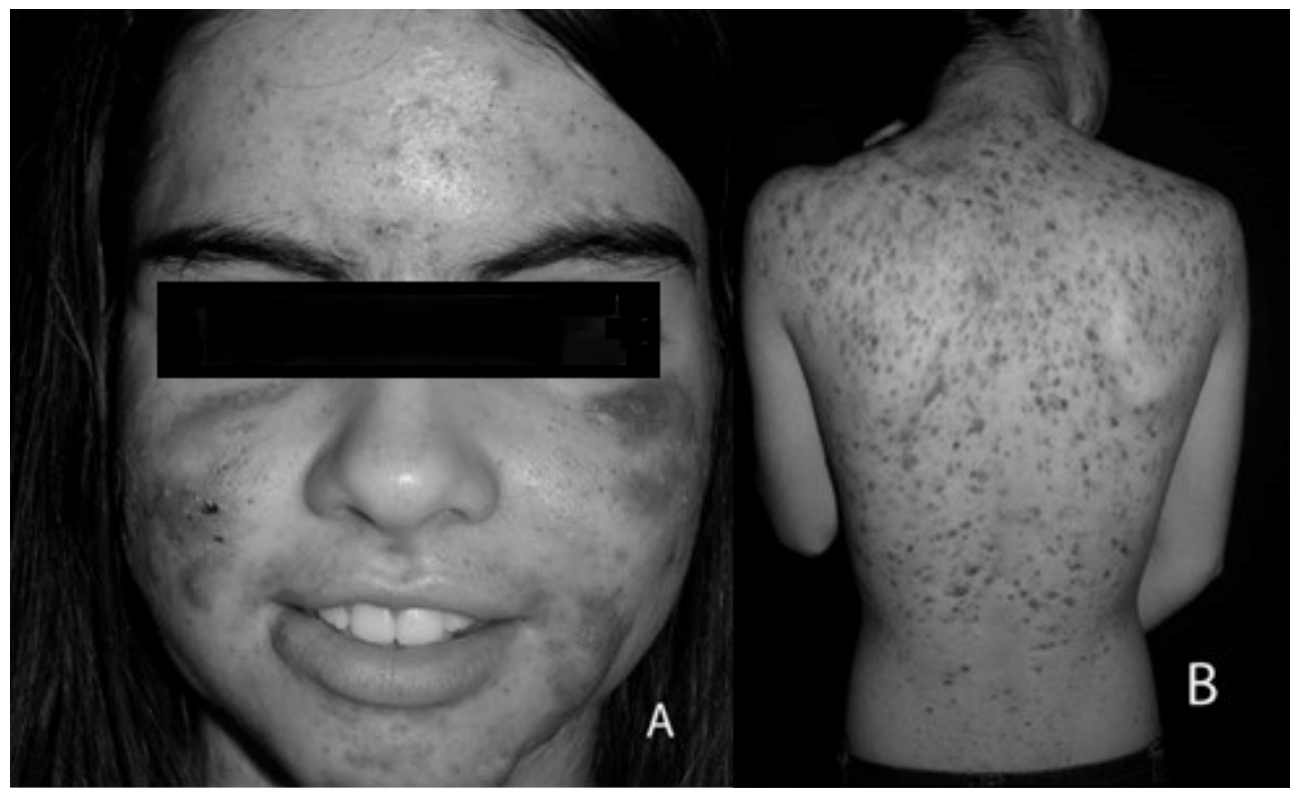

TABLE 1. NUMBER OF PATIENTS WITH ABNORMAL HORMONE LEVELS (N) AND PERCENTAGES BASED ON THE TOTAL NUMBER OF PATIENTS AND PATIENTS WITH ABNORMAL HORMONAL LEVELS. DHEA = DEHYDROEPIANDROSTERONE; DHT = DIHYDROTESTOSTERONE ; DHEAS = DEHYDROEPIANDROSTERONE SULFATE.

\begin{tabular}{|c|c|c|c|}
\hline Hormones & $n$ & $\begin{array}{l}\% \text { of total patients } \\
\text { (total of patients }=38 \text { ) }\end{array}$ & $\begin{array}{l}\% \text { among patients with abnormal hormonal } \\
\text { level (total of patients with abnormal levels =17) }\end{array}$ \\
\hline DHEA & 9 & $23.6 \%$ & $52.9 \%$ \\
\hline Androstenedione & 9 & $23.6 \%$ & $52.9 \%$ \\
\hline Testosterone & 4 & $10.5 \%$ & $23.5 \%$ \\
\hline DHT & 4 & $10.5 \%$ & $23.5 \%$ \\
\hline DHEAS & 2 & $5.26 \%$ & $11.7 \%$ \\
\hline
\end{tabular}




\section{DISCUSSION}

Acne is a fairly common complaint by female patients in dermatological clinics and remains a therapeutic challenge ${ }^{11}$. When adolescence starts, there is a physiological elevation of serum levels of androgens in both sexes ${ }^{2}$. These hormones promote the hypersecretion of sebaceous glands, the hyperkeratinization of the follicular ostium, and the modification of the sebum composition, influencing the proinflammatory events that are characteristic of acne vulgaris. In females, however, from the moment after ovulation is completely established, approximately two years after menarche, the estrogen levels promote the improvement of acne' .

A survey conducted with 2,895 women aged between 10-70 years of age showed that the peak incidence is in adolescence, being considered a disease characteristic of this stage of life ${ }^{11}$. However, when the acne is severe or extensive, in addition to greatly affecting the quality of life of patients, it may be a manifestation of hyperandrogenemia which, if left undiagnosed, can bring many damaging consequences during the adulthood of these patients, from an aesthetic perspective, because the inflammatory lesions and their potential to leave scars cause a significant social, educational, and functional impact, regardless of its severity $^{17}$, as well as from a metabolic perspective ${ }^{9}$.

Although androgens are related to the pathogenesis of acne, articles that correlate the elevation of its serum levels in women of childbearing age and acne are inconsistent in the literature, ranging from 30\% to $90 \%$ in some samples of patients, with an absence of changes in others ${ }^{3.18}$. Cunha et al. ${ }^{9}$, in a study with 835 patients, concluded that the serum levels of DHEA androgens, androstenedione, and testosterone, DHT and DHEAS must be part of a hormonal assessment in women above 15 years of age with acne, and that DHEA is the androgenic hormone with most frequently high levels. However, the study did not evaluate patients with severe acne with the onset of lesions between 9 and 15 years of age, as presented in this work.

The results obtained in this study showed that $44.7 \%$ of the total number of patients presented changes in the levels of androgens (hyperandrogenemia) and that the two exams that have abnormal results more frequently were the DHEA and androstenedione, with the same incidence (23.6\%). Cunha et al. ${ }^{9}$, in turn, found $56.5 \%$ of patients with androgenic changes, and $21.3 \%$ had changes in DHEA.
Hyperandrogenism plays an essential role, affecting approximately $5-10 \%$ of women of childbearing age worldwide ${ }^{19}$. Among the diseases that promote signs of increased androgen production in adult women, the most common is polycystic ovary syndrome (POS), which affects approximately $70-72 \%$ of the patients, followed by idiopathic hyperandrogenism in 15\%, idiopathic hirsutism in 10\%, and non-classic congenital suprarenal hyperplasia in $3 \%$. The estimated prevalence of disorders due to the excess of hormones in the general population is only possible for POS, and it varies between $4 \%$ and $14 \%$ in the female population since the prevalence of others, such as idiopathic hyperandrogenism or idiopathic hirsutism, unknown ${ }^{20}$. The clinical manifestations and laboratory findings in adolescents and adult women with POS and HCBSR share similarities. However, the differential diagnosis is essential to ensure that the therapeutic options can be individualized for each patient according to their needs ${ }^{21}$.

On the other hand, the POS diagnosis in adolescents remains controversial, and experts continue to discuss the appropriate diagnostic criteria ${ }^{22-26}$. The ideal age for POS investigation is still not established $^{23,}$ and several studies have shown that the incidence in adolescents is high and underdiagnosed ${ }^{26}$. Among the studies presented, Hickey et al. ${ }^{23}$ propose the age of 15.2 years as the threshold age, whereas Glueck et al. ${ }^{24}$ established it as 14 years old in their work. Bronstein et al. ${ }^{22}$, in turn, conducted a study in two populations: children under 13 years old and between 13-18 years to establish the age for diagnosis. They concluded that in patients with early puberty, 13 years old (or 1.5 years after pubarche and thelarche) should be considered in patients with clinical signs of hyperandrogenism.

In this study, the average age of lesion onset was 12.8 years, with one 9-year-old patient who met the inclusion criteria and, according to the criteria recommended by the Rotterdam consensus, $60.5 \%$ of the patients met the criteria for the POS diagnosis. Therefore, more important than the age of onset, the clinical condition of the patient must be considered; patients with severe acne, with or without evident signs of hyperandrogenism, must have their hormone levels evaluated to determine the best therapeutic conduct, which should be instituted as early as possible in order to avoid harmful manifestations in the future. 


\section{CONCLUSIONS}

The importance of a hyperandrogenemia diagnosis in cases of severe acne affecting patients between the ages of 9 and 15 years should be emphasized. The correct and early diagnosis provides an effective and agile approach, including antiandrogen therapy, to avoid reproductive and metabolic effects, in addition, to control the inflammatory process and avoid aesthetic complications, such as scars and dyschromia, improving the quality of life and reducing the morbidity and mortality in this group of patients.

\section{Contribution of the authors}

GC, CDMF, FLAF: Study design, data acquisition; CM, GC, RFS, SIFR: Data collection, analysis, and interpretation. All authors participated in the drafting, editing, and approval of the final version of the manuscript.

\section{RESUMO}

OBJETIVO: A acne vulgar em adolescentes do sexo feminino, quando grave ou acompanhada de outros sinais de androgenização, pode representar um sinal de hiperandrogenemia muitas vezes subdiagnosticado, que acarretará consequências danosas para a vida adulta. O objetivo deste estudo transversal e retrospectivo foi demonstrar a incidência das alterações hormonais nos casos de adolescentes do sexo feminino com acne grave ou extensa, acompanhada ou não de outros sinais de hiperandrogenismo e propor um padrão de pesquisa hormonal que deve ser indicado com o intuito de detectar precocemente o quadro de hiperandrogenemia.

MÉTODOS: Foram analisados os prontuários de 38 pacientes do sexo feminino com idades entre 9 e 15 anos, portadoras de quadro de acne grau II e/ou III. Os hormônios sulfato de dehidroepiandrostenediona, dehidroepiandrostenediona, androstenediona, testosterona total e dehidrotestosterona foram solicitados antes do início do tratamento. As dosagens hormonais foram realizadas no soro após pelo menos 3 horas de jejum por meio de exames de radioimunoensaio.

RESULTADOS: Das 38 pacientes incluídas, 44,7\% apresentaram alterações dos níveis de andrógenos (hiperandrogenemia), sendo que os dois hormônios mais frequentemente alterados foram o DHEA e androstenediona, com a mesma incidência (23,6\%).

CONCLUSÕES: O diagnóstico correto e precoce propicia uma abordagem efetiva e ágil, incluindo a terapia antiandrogênica, com a finalidade de evitar as repercussões reprodutivas e metabólicas, além de controlar o quadro inflamatório e evitar complicações estéticas.

PALAVRAS-CHAVE: Acne vulgar. Adolescente. Androgênios. Hiperandrogenismo.

\section{REFERENCES}

1. Zouboulis CC, Chen WC, Thornton MI, Qin K, Rosenfield R. Sexual hormones in human skin. Horm Metab Res. 2007;39(2):85-95.

2. Karrer-Voegeli S, Rey F, Reymond MI, Meuwly IY, Gaillard RC, Gomez F. Androgen dependence of hirsutism, acne and alopecia in women: retrospective analysis of 228 patients investigated for hyperandrogenism. Medicine (Baltimore). 2009;88(1):32-45.

3. Strauss |S, Krowchuk DP, Leyden \|, Lucky AW, Shalita AR, Siegfried EC, et al; American Academy of Dermatology/American Academy of Dermatology Association. Guideline of care for acne vulgaris management. J Am Acad Dermatol. 2007;56(4):651-63.

4. Thiboutot D. Acne: hormonal concepts and therapy. Clin Dermatol. 2004;22(5):419-28.

5. Zouboulis $\mathrm{cC}$, Degitz K. Androgen action on human skin: from basic research to clinical significance. Exp Dermatol. 2004;13(Suppl 4):5-10.

6. Farrar MD, Ingham E. Acne: inflammation. Clin Dermatol. 2004;22(5):380-4.

7. Kurokawa I, Danby FW, Ju Q, Wang X, Xiang LF, Xia L, et al. New developments in our understanding of acne pathogenesis and treatment. Exp Dermatol. 2009;18(10):821-32.

8. Thiboutot D. Regulation of human sebaceous glands. J Invest Dermatol. 2004;123(1):1-12

9. Cunha $\mathrm{mG}$, Fonseca FL, Machado CD. Androgenic hormone profile of adult women with acne. Dermatology. 2013;226(2):167-71.

10. Tilles G. Acne pathogenesis: history of concepts. Dermatology 2014;229(1):1-46

11. Kamangar F, Shinkai K. Acne in the adult female patient: a practical approach. Int J Dermatol. 2012;51(10):1162-74
12. Goulden V, Clark SM, Cunliffe W]. Post-adolescent acne: a review of clinical features. Br J Dermatol. 1997;136(1):66-70.

13. Cunliffe WJ, Gollnick HPM. Acne diagnosis and management. London: Martin Dunitz; 2001. p.56-9.

14. Cunha MG Rezende FC, Cunha ALG, Machado CA, Fonseca F. Anatomica, histological and metabolic differences between hypodermis and scutaneus adipose tissue. Int Arch Med. 2017;10(152):1-6.

15. Elmlinger MW. Laboratory measurements of hormones and related biomarkers: technologies, quality management and validation. In: Mullis PE, Ranke MB, eds. Diagnostics of endocrine function in children and adolescents. Basel: Karger Publications; 2011. p.1-31.

16. Rotterdam ESHRE/ASRM-Sponsored PCOS Consensus Workshop Group. Revised 2003 consensus on diagnostic criteria and long-term health risks related to polycystic ovary syndrome. Fertil Steril. 2004;81(1):19-25.

17. Williams C, Layton AM. Persistent acne in women: implications for the patient and for therapy. Am J Clin Dermatol. 2006;7(5):281-90.

18. Timpatanapong $P$, Rojanasakul A. Hormonal profiles and prevalence of polycystic ovary syndrome in women with acne. J Dermatol. 1997;24(4):223-9.

19. Shaw JC. Acne: effect of hormones on pathogenesis and management. Am | Clin Dermatol. 2002;3(8):571-8.

20. Sanchón R, Gambineri A, Alpañés M, Martínez-García MÁ, Pasquali R, Escobar-Morreale HF. Prevalence of functional disorders of androgen excess in unselected premenopausal women: a study in blood donors. Hum Reprod. 2012;27(4):1209-16. 
21. Tuten A, Sahmay S, Oncul M, Acikgoz AS, Imamoglu M, Gurleyen HC, et al. Serum AMH levels in the differential diagnoses of hyperandrogenemic conditions. Eur J Obstet Gynecol Reprod Biol. 2014;177:121-5.

22. Brostein J, Tawdekar S, Liu Y, Pawelczak M, David R, Shah B. Age of onset of polycystic ovarian syndrome in girls may be earlier than previously thought. J Pediatr Adolesc Gynecol. 2011;24(1):15-20.

23. Hickey M, Doherty DA, Atkinson H, Sloboda DM, Franks S, Norman RJ, et al. Clinic, ultrasound and biochemical features of polycystic ovary syndrome in adolescents: implications for diagnosis. Hum Reprod. 2011;26(6):1469-77.
24. Glueck CJ, Morrison JA, Daniels S, Wang P, Stroop D. Sex hormone-binding globulin, oligomenorrhea, polycystic ovary syndrome, and childhood insulin at age 14 years predict metabolic syndrome and class III obesity at age 24 years. | Pediatr. 2011;159(2):308-13.

25. Catteau-Jonard S, Cortet-Rudelli C, Richard-Proust C, Dewailly D. Hyperandrogenism in adolescent girls. Endocr Dev. 2012;22:181-93.

26. Shannon M, Wang Y. Polycystic ovary syndrome: a common but often unrecognized condition. J Midwifery Womens Health. 2012;57(3):221-30. 